\title{
An allometric analysis of the giraffe cardiovascular system.
}

\author{
G Mitchell $^{1,2 *}$, JD Skinner ${ }^{1}$
}

Centre for Veterinary Wildlife Studies, Onderstepoort, South Africa ${ }^{1}$, and Department of Zoology and Physiology, University of Wyoming, Laramie, WY 82071, USA².*Author for correspondence: email mitchg@uwyo.edu. Present address Department of Physiology and Pharmacology, University of Bristol, UK.

\begin{abstract}
There has been co-evolution of a long neck and high blood pressure in giraffes. How the cardiovascular system (CVS) has adapted to produce a high blood pressure, and how it compares with other similar sized mammals largely is unknown. We have measured body mass and heart structure in 56 giraffes of both genders ranging in body mass from $18 \mathrm{~kg}$ to $1500 \mathrm{~kg}$, and developed allometric equations that relate changes in heart dimensions to growth and to cardiovascular function. Predictions made from these equations match measurements made in giraffes. We have found that heart mass increases as body mass increases but it has a relative mass of $0.51 \pm 0.7 \%$ of body mass which is the same as that in other mammals. The left ventricular and interventricular walls are hypertrophied and their thicknesses are linearly related to neck length. Systemic blood pressure increases as body mass and neck length increase and is twice that of mammals of the same body mass. Cardiac output is the same as, but peripheral resistance double that predicted for similar sized mammals. We have concluded that increasing hydrostatic pressure of the column of blood during neck elongation results in cardiac hypertrophy and concurrent hypertrophy of arteriole walls raising peripheral resistance, with an increase in blood pressure following.
\end{abstract}

Key words: Giraffes, hypertension, allometry, heart anatomy, heart function

\section{Introduction}

Most physiologists confronted by the long neck and legs of giraffes are struck by the physiological problems giraffe anatomy imposes on its circulatory system. These problems include how blood reaches the head, how orthostatic hypotension (fainting) and dependent oedema are prevented, and how cranial blood flow and 
venous return from the head and feet are regulated.

Many of the mechanisms that have evolved in giraffes to solve these problems have been analyzed. For example, the possibility that a siphon assists blood flow to the head (Badeer, 1986; 1988; 1997; Badeer \& Hicks, 1992) has been disproved by several analyses (Holt, 1959; Seymour \& Johansen, 1987; Seymour et al, 1993; Pedley et al, 1996; Munis \& Lozada, 2000; Seymour, 2000; Mitchell et al, 2006). Blood delivery to the head is now known to depend solely on the magnitude of arterial blood pressure (Goetz, 1955; Goetz \& Budtz-Olsen, 1955; Patterson et al, 1965; Mitchell et al, 2006). When a giraffe lifts its head fainting is prevented by a unique anastomosis between the carotid and vertebral arteries (Lawrence \& Rewell,1948) that directs carotid artery blood into the cerebral circulation (Goetz \& Keen, 1957), and an increase in cerebral perfusion pressure arising from drainage of cerebral venous blood into non-collapsible vertebral venous plexus veins (Zippel et al, 2001; Hicks \& Munis, 2005; Mitchell et al, 2008). Jugular vein valves prevent regurgitation of venous return into the cranial circulation and divert it into the right atrium (Mitchell et al, 2009). Dependent oedema is prevented by well-developed venous return mechanisms in the feet and legs and a tight non-elastic skin (Hargens et al, 1987; 1988; Mitchell \& Hattingh, 1993). All these analyses have relied for their data on measurements made in a few captured giraffes and in mechanical models. They have not elucidated how the mechanisms develop with growth, nor do they allow an appreciation of how the giraffe heart and cardiovascular system compare with those of similar sized mammals. Thus, it remains unclear what the adaptive changes within the cardiovascular system are that have evolved to support the evolution of a long and elevated neck.

For mammals, including giraffes, a primary function of the cardiovascular system is to maintain cerebral blood flow, a function achieved by a mean arterial blood pressure (MAP) of ca100mmHg at the head (Schmidt-Nielsen, 1984). For most mammals the vertical distance between the heart and the head is small, or increases comparatively little as neck length increases with increases in body size (Seymour \& Blaylock, 2000). Thus in them pressure at the head is similar to that at the heart. Giraffes have a uniquely long neck and must generate an arterial blood pressure sufficient to overcome the gravitational, hydrostatic, pressure 
exerted on the heart by the vertical height of the column of blood in neck arteries, mainly the carotid artery (Goetz, 1955; Goetz \& Keen, 1957; Mitchell et al, 2006). The pressure develops progressively as their necks elongate, as giraffes are not born with the high blood pressure needed to deliver blood to the head when they are adults (Keen \& Goetz, 1957; Hargens et al, 1988). The high arterial pressure exposes giraffes to the effects of hypertension, and mechanisms to prevent the consequences of hypertension must develop in tandem with increasing blood pressure. It follows that the structure of the cardiovascular system and the heart specifically, must change with growth and must scale differently to that in other shorter necked mammals. These facts are widely recognized (Stahl, 1967; Holt et al, 1968; Calder, 1996; Seymour \& Blaylock, 2000), although the details are unknown.

We have, therefore, collected morphological data with the aim of illustrating the physiological specializations of the cardiovascular system that giraffes have evolved and to show how they change between fetal life and adult maturity.

\section{Method}

We have approached this study by developing allometric equations to describe relationships between markers of growth, morphological changes we have measured, and physiological data reported in other studies. Our analyses are based on data collected from 56 giraffes culled in southeastern Zimbabwe in each April and November between 2006 and April 2009. No institutional animal care approval was required for this study. Animals were culled according to the legal requirements of Zimbabwe. Immediately after being shot the following measurements were made:

Body Mass $(\mathrm{Mb}, \mathrm{kg})$. We have used two methods to determine body mass to take into account loss of tissue during dissection and interseasonal variation. First, before any dissection took place we measured length and girth in metres and calculated body mass from regression equations developed for giraffes by Hall-Martin (1977). For giraffes these equations are: 
Males: $26.117^{*} L^{*} G^{2}+33.945$

Females: $25.400 * L^{*} G^{2}+66.109$

Both: $25.902 * L^{*} G^{2}+45.758$

where $\mathrm{L}$ is total length measured from the tip of the nose to the tip of the tail and $\mathrm{G}$ the girth of the thorax measured immediately caudal to the front legs. Secondly, we weighed the giraffes piecemeal by weighing all body parts, including viscera and skin. The body mass of giraffes used in our analyses was the mean of the mass calculated from the relevant gender specific equations and the mass obtained from direct piecemeal weighing.

Neck Length $(\mathrm{cm})$ was the mean of the distances from the occipital crest to the withers and from the angle of the jaw to the acromion.

Heart Dimensions. Heart mass (Mh, $\mathrm{g}$ ) was measured after removal of the pericardium and adnexal adipose tissue, after the large blood vessels were cut off at the level of the atria, and after as much blood as possible could be removed from the ventricles. Heart length $(\mathrm{mm})$ was the length from the level of the junction of atria and ventricles (the coronary band) to the apex. The external diameter of the heart (width, $\mathrm{mm}$ ) was measured at the coronary band along the interventricular septum after removal of the atria. Ventricular wall thicknesses $(\mathrm{mm})$ were measured at the midpoint of the ventricles after the heart had been transected there (see Fig 2).

Systemic Blood Pressure (mmHg). Giraffe systemic blood pressure measured at the level of the heart is directly correlated with neck length (Goetz, 1955; Goetz \& Keen, 1957; Mitchell et al, 2006). For each giraffe we calculated blood pressure by adding to allometric predictions of blood pressure from body mass (Calder, 1996; Seymour \& Blaylock, 2000) the pressure generated by a vertical column of blood in the carotid artery. The vertical height is the product of neck length and the angle of carry of the neck. We 
computed blood pressure for all angles of the neck between $30^{\circ}$ and $90^{\circ}$. Pulse pressure at rest in unanaesthetized giraffes is ca60mmHg (Goetz et al, 1960; van Citters et al, 1969) from which estimates of systolic and diastolic pressures for our giraffes were made assuming that mean pressure is diastolic pressure plus one-third of pulse pressure.

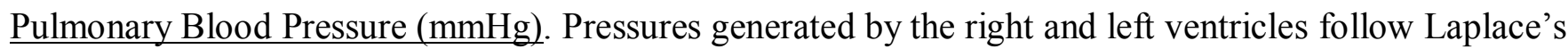
Law (although not precisely (Seymour \& Blaylock, 2000)) and are proportional to wall thickness divided by radius (Calder, 1981; Seymour \& Blaylock, 2000). From the ratio of left ventricle wall thickness to its diameter and the mean blood pressure it produces, and from the ratio of right ventricle diameter and its wall thickness, we calculated mean pulmonary pressure for each giraffe. Pulmonary pulse pressure in giraffes is ca25mmHg (Goetz et al, 1960) and using this value estimates of systolic and diastolic pressures were made for each giraffe.

Peripheral Resistance. Systemic peripheral resistance was computed from cardiac output (CO) and mean systemic blood pressure for each animal, and pulmonary resistance from $\mathrm{CO}$ and mean pulmonary artery pressure. CO was calculated from body mass (Stahl, 1967; Calder, 1996).

Comparisons. Each measurement we made or calculated was compared with predictions made from allometric equations for mammals generally and with the relatively few actual measurements made in giraffes. The sources for the mammal allometric equations were Stahl (1967), Holt et al (1968) whose equations used both body mass and heart mass as allometric covariates, Prothero (1979), Calder (1981;1996), and Seymour and Blaylock (2000). Predictions calculated from these equations differ slightly. Thus, each of them was used to make predictions for the giraffes in our sample. Generic (combined) allometric equations were derived from the means of these predictions and used in our comparisons.

$\underline{\text { Statistical analyses }}$ All data were entered into an Excel spreadsheet for analysis. As the relationship between body dimensions and organ dimensions is non-linear, data were log transformed for linear regression 
(Prothero, 1979; Calder, 1996) and the results used to develop allometric equations of the form $y=a^{*} M^{b}$, where $a$ is the intercept, $M$ body mass in $\mathrm{kg}$, and $b$ the slope, or $y=a^{*} N L^{b}$, where NL is neck length. From these equations trend curves showing how changes in specific variables correlate with changes in $\mathrm{Mb}$ or $\mathrm{NL}$ were plotted. Differences between giraffe and predicted values were evaluated by analysis of variance (Ftest) and correlation analysis. P values $<0.05$ were regarded as significant.

\section{Results}

No significant differences were found between same-body mass males and females. Therefore the data were pooled.

Body mass. Table 1 summarizes the characteristics of the animals from which the data were collected. Body mass ranged from $18 \mathrm{~kg}$ in a midterm fetus (gestational age 274 days) to old, mature animals of both genders. Body mass range differed by four-fold amongst the fetuses, 10 fold amongst postnatal animals and 80 fold between the smallest and largest animals.

Heart dimensions. Table 2 shows the allometric relationships between body mass and each of the structural components of the cardiovascular system, together with the general mammal equations for heart mass, the Mh:Mb ratio, and left ventricle wall thickness. Also described are the relationships between left ventricle and interventricular wall thickness and neck length. All equations have an $\mathrm{R}^{2}$ value in excess of 0.90 . Heart mass increases almost linearly with body mass in both adults and fetuses, and the highest heart mass we found was $7.8 \mathrm{~kg}$ in a $1441 \mathrm{~kg}$ male giraffe. The relative heart mass (Mh:Mb ratio) declined with growth (Fig 1A) and was on average $0.51 \pm 0.7 \%$ which was not significantly different from that of mammals in general (Table 2; 4; Fig 1A). During growth the heart elongates and widens 4-5 fold (Table 4). Left ventricle and interventricular wall thicknesses increase markedly during growth reaching a maximum of $8 \mathrm{~cm}$ and $5.7 \mathrm{~cm}$ respectively in our giraffes, and increase significantly more than the hypertrophy predicted form the general mammal equation (Tables $2 \& 4$; Fig. 1B). Hypertrophy of the ventricle walls correlates with increases in neck length (Table 2; Fig.1D), and with hypertrophy of the tunica media of arterioles (Fig 2).

Dynamic variables The allometric relationships between body mass and each of the dynamic variables we 
computed are shown in Table 3 together with the general mammal equations for the variables. These equations also have $\mathrm{R}^{2}$ values greater than 0.90 . From the equations for giraffes we calculated typical values for a 775kg giraffe and for the range of values likely to be found in fetal and adult giraffes of the body mass range in our sample (Table 4). The key cardiovascular variable in giraffes is arterial blood pressure. How mean, systolic, and diastolic arterial pressure and pulmonary arterial pressure change during growth and how they compare to mean systemic pressure in other mammals is shown in Figure 1C. All giraffe blood pressures in giraffes are higher than predicted for mammals of similar body mass. Blood pressure depends on cardiac output and resistance to blood flow. Our data suggest that cardiac output is similar to that in other mammals but the resistance to blood flow in both the systemic and pulmonary circulations is higher (Table 4).

\section{Discussion}

It is well-established that the systemic (arterial) blood pressure (MAP) of giraffes is high and must be able to increase during growth as an essential prerequisite for neck elongation. Our calculations of systemic blood pressure at the level of the heart when the neck is at $55^{\circ}$ to the vertical, give a value for it of $208 \mathrm{mmHg}$ in a giraffe of the average body mass of giraffes in our study $(775 \mathrm{~kg})$ (Table 4; Fig 1C). This pressure is almost twice the predicted value for animals of similar body mass $(116.5 \mathrm{mmHg}$; Fig. 1C). Blood pressure in giraffes varies depending on the angle of the neck to the vertical. At an angle of $30^{\circ} \mathrm{MAP}$ can be predicted to be $187 \mathrm{mmHg}$ in a $775 \mathrm{~kg}$ giraffe, $216 \mathrm{mmHg}$ at $60^{\circ}$ and $247 \mathrm{mmHg}$ at $90^{\circ}$. Blood pressure also depends on neck length. Systemic blood pressure at birth in a giraffe (= a body mass of 100kg; Skinner \& Hall-Martin, 1975) is the same as in other mammals but as giraffe grow and their neck elongates it rises (Fig. 1C).

These predicted blood pressures lie within the range of measured values. There are 29 measurements of giraffe systemic blood pressure reported in the literature and they were made in animals that had a similarly wide range of body masses and of neck lengths and angles as our giraffes. These measurements give an average systemic blood pressure of $203 \pm 41 \mathrm{mmHg}$ (Goetz, 1955; Goetz \& Keen, 1957; Goetz et al, 1960; Patterson et al, 1957; 1965; van Citters et al, 1966, 1968;1969; McCalden et al, 1977; Millard et al, 1986; 
Hargens et al, 1987; Mitchell \& Skinner, 1993; Linton et al, 1999). Using the same sources pressure at the head can be calculated to be $100 \pm 21 \mathrm{mmHg}$ (Mitchell \& Skinner, 1993), which is the same as that in all other mammalian species and is the pressure required to achieve adequate cerebral perfusion (Schmidt-Nielsen, 1984). Our data suggest that high blood pressure is not confined to the systemic circulation. Pulmonary artery pressure has been reported twice in giraffe and was found to be between $38 / 13 \mathrm{mmHg}$ and $48 / 22$ mmHg in one study (Goetz et al, 1960) and 75/25 mmHg in another (Patterson et al, 1957). Our calculations show that mean pulmonary pressures decline through foetal life and rise slowly after birth (Fig. 1C). In a $775 \mathrm{~kg}$ giraffe pulmonary blood pressure is $38 \mathrm{mmHg}$ compared to ca $15 \mathrm{mmHg}$ in other mammals.

The origin of these high pressures is controversial. As blood pressure is the product of cardiac output and the resistance to blood flow, one hypothesis for the high blood pressure is that giraffes have a very large heart producing a high cardiac output (Goetz, 1955). An alternative hypothesis is that resistance to blood flow is high because the internal diameters of arteries and arterioles below the level of the heart are reduced as a response to gravitational hydrostatic pressure. The increased resistance raises arterial pressure (Badeer, 1997). A third hypothesis is that high blood pressure is a regulated response to maintain cerebral blood flow which simultaneously causes cardiac hypertrophy and increased arteriolar resistance (Paton et al, 2009). With respect to the first of these hypotheses an important finding we report is the mass of the heart. A heart mass of 11.25kg found by Goetz (Goetz, 1955; Goetz \& Keen, 1957) in a giraffe estimated to weigh $500 \mathrm{~kg}$ entrenched the idea that a large heart was the source of the high blood pressure of giraffes. The relative mass of this heart was ca $2.5 \%$ or five times that predicted for other mammals. This measurement has remained the benchmark for even recent articles on the giraffe cardiovascular system (Seymour \& Blaylock, 2000) but our data show that it was in all probability an error of measurement. Our data confirm four earlier measurements of giraffe heart mass made by Crisp in 1864 (Crisp, 1864a, 1864b) in which Mh: Mb of 0.3\% to $0.6 \%$ were found, and another of a $4990 \mathrm{~g}$ heart in a giraffe with an estimated body mass of $1220 \mathrm{~kg}$ (Altman \&Dittmer,1971) for an Mh:Mb of 0.41\%. Our data show that on average Mh: Mb for the 56 giraffes in our study was $0.51 \pm 0.07 \%$. Our average is not significantly different to the average predicted for all mammals of equivalent body mass $(0.55 \pm 0.02 \%)$. However, the way the average is produced in giraffes 
differs from that of other mammals (Fig.1A). In giraffes, Mh: Mb decreases gradually as Mb increases with the highest ratio occurring in fetuses and the lowest ratio in the largest animals. Predicted ratios for $\mathrm{Mh}: \mathrm{Mb}$ show the opposite pattern (Fig. 1A), probably because analyses of fetal heart mass have not been included in other studies. The fetal heart in giraffes is relatively much bigger than it is in adults, a relationship that is probably true for all mammals as implied by Holt et al (1968).

Although the giraffe heart is not larger than expected, our measurements show that its internal structure is quite different to that of other mammals. The most significant differences are the thicknesses of the left ventricular (LVW) and interventricular (IVW) walls (Fig. 1B; 2). We are not aware of any previous allometric description of the thickness of the IVW or for the right ventricular wall (RVW), but our data suggest that both hypertrophy but not to the same extent as the LVW (Fig. 1B; 2). When the LVW and IVW are compared to those in other mammals the difference in thickness is obvious (Figs. 1B; 2). Both are massively hypertrophied in giraffes, a process that our data show is gradual and starts after birth (Figs. 1B; 2). The thickness is related almost linearly to the length of the neck (Table 2; Fig 1D). As neck length in giraffes and their blood pressure are correlated (Goetz, 1955; Mitchell et al, 2006), hypertrophy of the ventricle walls is likely to be a response that normalizes wall tension (Seymour \& Blaylock, 2000). These walls are the genesis of the spectacular contraction characteristics of the giraffe heart characterized by a $\mathrm{dp} / \mathrm{dt}$ of $6000 \mathrm{mmHg} \cdot \mathrm{sec}^{-1}$ which is two-and-a-half times that in a cow and five times that of humans (Patterson et al, 1965).

Given that the heart is not relatively larger in giraffes than in other mammals, our findings indicate that it has evolved to be highly functional and it is possible, therefore, that it can and does generate a high cardiac output (CO). However, CO scales allometrically with body mass (Patterson et al, 1965; Stahl, 1967; Calder, 1981; Schmidt-Nielsen, 1984). Thus giraffe CO should reflect their mass and not their anatomy, and should not be unusual. CO has been measured eight times in five giraffes (Goetz et al, 1960; Linton et al, 1999) and the range of CO reported is wide. In one of Goetz et al's (1960) giraffes, for example, two measurements, each using a different technique for measuring $\mathrm{CO}$, gave values for $\mathrm{CO}$ of $75 \mathrm{~L} / \mathrm{min}$ and $39.1 \mathrm{~L} / \mathrm{min}$, and in 
another giraffe $\mathrm{CO}$ was measured to be $32 \mathrm{~L} / \mathrm{min}$ and $22 \mathrm{~L} / \mathrm{min}$. These giraffes were restrained, not anaesthetized or sedated, and thus the variation may reflect anxiety. Linton et al (1999) measured CO twice in an anaesthetized giraffe weighing an estimated $800 \mathrm{~kg}$ and found it to be $19.7 \mathrm{~L} / \mathrm{min}$ and $20.3 \mathrm{~L} / \mathrm{min}$. These values were regarded as being low (Linton et al, 1999). Further uncertainty arises from an allometric equation developed by Patterson et al (1965) for a range of mammals including giraffes $\left(\mathrm{CO}=0.1017^{*} \mathrm{Mb}^{0.9988}\right)$ that predicts a CO twice what the equations of Calder (1996), Stahl (1967), Holt et al (1968) and Seymour and Blaylock (2000) predict. However, when we compared the CO predicted by the general mammalian equation (Table 3) for giraffes of ca500kg body mass studied by Goetz et al (1960) the equation predicts a $\mathrm{CO}$ of $27 \mathrm{~L} \cdot \mathrm{min}^{-1}$, which is in the range of $\mathrm{CO}$ that was measured. For Linton et al's (1999) giraffe CO would be 39L. $\mathrm{min}^{-1}$ which is a far more realistic value for an animal of this size. On average the $\mathrm{CO}$ predicted from mammalian allometric equations was $5.1 \mathrm{~L} .100 \mathrm{~kg}^{-1}$ of body mass for the giraffes in our sample. We have concluded that there is no reason to suspect that $\mathrm{CO}$ is different in giraffes to other mammals of similar body size and that it is not specialized in giraffes.

Cardiac output is the product of stroke volume (SV) and heart rate (HR). HR scales with metabolic rate (Holt et al, 1968). This may explain why of all the dynamic variables reported for giraffes HR varies most widely. HR has been measured in giraffes that were sedated or anaesthetized, struggling or restrained, recumbent or standing, all involving different metabolic rates, and all of them circumstances that produce meaningless estimates of basal heart rate (but giving of course some idea of what maximal heart rates might be). For example, in one restrained giraffe heart rate was found to be 100bpm (Goetz, 1955; Goetz \& BudtzOlsen, 1957). In four restrained but not sedated giraffes average HR was found to be $85 \pm 13 \mathrm{bpm}$ with a range of 65 to 105bpm (Goetz \& Keen, 1957), and in anaesthetized animals 70-97bpm (Jefferson, 1971; Rossof, 1972). In free ranging animals, with HR recorded by telemetry, HR of 40bpm (standing quietly), 60bpm (prone) and 175bpm (galloping) have been recorded (van Citters et al, 1969). In nine animals accustomed to being handled and unanaesthetized, HR was found to be $81 \pm 15.2$ (Langman, 1973). A general conclusion possible from these studies seems to be that giraffes' HR at rest typically is between 60 to $90 \mathrm{bpm}$ rising to $175 \mathrm{bpm}$ during exercise. 
The range for HR in our adult giraffes predicted from the equations of Stahl (1967), Holt et al, (1968), Seymour and Blaylock (2000), and Calder (1996) is 29-71bpm (mean 47bpm), or approximately two-thirds of measured values. This discrepancy could arise because the structure of the giraffe heart is different to that of normal mammals and that stroke volume is smaller than predicted. So far, SV has not been measured directly in giraffes but has been inferred from CO and HR, with Goetz et al (1960) recording a SV of approximately $700 \mathrm{ml}$ in one giraffe, although an average of $494.6 \pm 215.8$ (range $258-807 \mathrm{ml}$ ) can be inferred from those data. We have calculated SV from body mass and heart mass using Stahl's (1967), Holt et al's (1968), and Seymour and Blaylock's (2000) equations. The range of SV determined for our giraffes by this method was $247-1972 \mathrm{ml}$ (mean $818 \mathrm{ml}$ ). These equations predict that for the three ca500kg giraffes in Goetz et al's study (1960) SV would be ca525ml, a value within the $258-807 \mathrm{ml}$ range that can be calculated for them, and for Linton et al's $800 \mathrm{~kg}$ giraffe an SV of $840 \mathrm{ml}$ whereas the inferred value was $800 \mathrm{ml}$. These calculations suggest that giraffe SV scales with body mass and heart mass as it does in other mammals and shows no specialization. However, it is almost certainly the case that SV decreases in proportion to increases in left ventricular wall hypertrophy (Fig. 2). If so then heart rate will increase proportionately. When we calculated SV assuming that it did decrease in proportion to left ventricular hypertrophy, the SV of the giraffes fell to $87-1117 \mathrm{ml}$ (mean $572 \mathrm{ml}$; $\mathrm{SV}=0.55^{*} \mathrm{Mb}^{1.04}$ ) from the predicted $818 \mathrm{ml}\left(\mathrm{SV}=1.05 * \mathrm{Mb}^{1.0}\right)$, and consequently average heart rate increased to $70 \mathrm{bpm}\left(\mathrm{HR}=418.2 * \mathrm{Mb}^{-.28}\right)$. When we applied these equations to Goetz et al's (1960) and Linton et al's (1999) giraffe data, SV was calculated to be $353 \mathrm{ml}$ and $574 \mathrm{ml}$ respectively. Whether SV is smaller and HR higher than predicted will be resolved only when several accurate measurements of cardiac output and heart rate are made in free-ranging giraffes over a substantial period of time. We have concluded, however, that SV in giraffe is likely to be lower than predicted values and heart rate higher than predicted values, both effects resulting from left ventricular wall hypertrophy.

As $\mathrm{CO}$ is relatively the same in giraffes as in other mammals but arterial blood pressure high, resistance to blood flow must be high. The range of systemic resistance we calculated from $\mathrm{CO}$ and blood pressure for our giraffes assuming that their necks were at the typical angle of carry of $55^{\circ}$ to the vertical (Dagg, 1962), 
was $4-14 \mathrm{mmHg} \cdot \mathrm{L}^{-1} \cdot \mathrm{min}^{-1}\left(\right.$ mean=5.5) compared with a predicted range of $2-10 \mathrm{mmHg} \cdot \mathrm{L}^{-1} \cdot \mathrm{min}^{-1}(\mathrm{mean}=3.5)$ for mammals of similar body mass (Fig. 1D). The origin of the higher resistance to blood flow in giraffes could be gravitational pressure as suggested by Badeer (1997). The higher resistance correlates with hypertrophy of vessel walls in peripheral arteries and arterioles lying at or below the level of the heart (Fig. 2). Arterioles situated above the level of the heart are less affected (Keen \& Goetz, 1957; Hargens et al, 1988; Kimani et al, 1991), which suggests that hypertrophy of blood vessel walls is a response to high blood pressure. Its effect is to reduce blood flow to dependent tissues to appropriate levels (Hargens et al, 1987). However, we do not believe that this is the cause of vessel hypertrophy, firstly because other long legged mammals such as camels and elephants whose dependent blood vessels are also subjected to gravitational hydrostatic pressure do not have high peripheral resistance. Secondly, the rise in blood pressure is regulated to match neck length, which suggests that a receptor-response reflex is operative. This Cushings mechanism senses blood flow to the brain stem and its effect is coordinated hypertrophy of cardiac muscle and arterioles to minimize energy expenditure (Paton et al, 2009). The vessel hypertrophy causes increased resistance of structural origin that is passive and described by La Place's Law (Folkow, 1991), but the vessels retain enough neurogenic control to regulate changes in blood pressure and flow required by postural changes and other demands such as exercise (Nilsson et al, 1988; Kimani et al, 1991). Pulmonary resistance in giraffes is $0.3-1.3 \mathrm{mmHg} \cdot \mathrm{L}^{-1} \cdot \mathrm{min}^{-1}$ (mean=0.9), which is one-seventh of systemic resistance i.e. the same relative value to systemic resistance as it is in other mammals, but its absolute value is twice what it is in other mammals of similar body mass. This finding suggests that pulmonary resistance vessels also respond by hypertrophy to prevailing pulmonary blood pressures or that the mechanism producing arteriole hypertrophy (Paton et al, 2009) does not distinguish between systemic and pulmonary arterioles.

In summary our data have eliminated a source of controversy (the size of the giraffe heart) and have defined, and provided an allometric description of, the growth and structure of the giraffe heart and in particular ventricle wall thicknesses. Our data suggest that the physiological hypertension of giraffes originates with the gravitational back pressure of the arterial blood column in the neck. They support the idea that the physiological response to neck elongation is cardiac hypertrophy, not cardiac enlargement or an increase in 
cardiac output. They also support the hypothesis that in parallel with cardiac hypertrophy, and as part of a coordinated reflex, arteries and arterioles at or below the level of the heart, hypertrophy. They do so because they are exposed to high pressure of both cardiac and gravitational origin and to the effects of autonomic regulation of resistance. Increased blood pressure results from a balance between cardiac hypertrophy and increased arteriole resistance. Its magnitude is regulated to maintain sufficient cerebral blood flow. Blood flow to tissues that would otherwise be subjected to extraordinary pressure and flows is regulated by arteriole hypertrophy. With respect to the dynamic functions of the cardiovascular system we have concluded that cardiac output is as expected for animals of the size of giraffes but that stroke volume is likely to be smaller than predicted values and heart rates correspondingly higher than predicted. In general our study suggests that giraffes have a small but powerful heart and that the cardiovascular system of giraffes is specialized, differs in several respects to other mammals, but is adapted in ways that minimize the energetic cost of the stresses placed on it by their extraordinary shape.

Acknowledgements. We thank the management and staff of the Bubye Valley Conservancy, Zimbabwe for their logistical support and sponsorship of this study. Additional funds were provided by the Don Craib Trust (JDS), from a personal research grant (JDS) and the University of Wyoming (GM). Technical field support was provided by Sybrand van Sittert, Carl-Heinz Moeller, Kenneth Manyangadze, Mark Brewer, Lauren Leathem, David Roberts, Kyle Pearse, Declan Gallagher, and Blake Wilelmi. We are grateful to Profs Julian Paton and Roger Seymour for their comments on earlier drafts of this article.

\section{References}

Altman, P.L. \& Dittmer D.S. 1971. Respiration and circulation. FASEB, Bethesda, Maryland. p235.

Badeer, H.S. 1986. Does gravitational pressure of blood hinder flow to the brain of the giraffe. Comparative Biochemistry and Physiology A. 83: 207-211.

Badeer, H.S. 1988. Haemodynamics of the jugular vein in the giraffe. Nature 332:788-789.

Badeer, H.S. 1997. Is the flow in the giraffe's jugular vein a "free" fall? Comparative Biochemistry and Physiology A. 118(3): 573- 576.

Badeer, H.S. \& Hicks, J.W. 1992. Hemodynamics of vascular "waterfall": is the analogy justified? Respiration Physiology 87: 205-217. 
Calder, W.A. 1981. Scaling of physiological processes in homeothermic animals. Annual Reviews of Physiology. 43:301-322.

Calder, W.A. 1996. Size, Function, and Life History. Dover Publications, Inc. Mineola, New York.

Crisp, E. 1864a. Contributions to the anatomy of the giraffe, with an account of the length of the alimentary canal of many other ruminants. Proceedings of the Zoological Society (London) pp63-68.

Crisp, E. 1864b. Further contributions to the anatomy of the giraffe and the nylghau. Proceedings of the Zoological Society (London) pp269- 271.

Dagg, A.I. 1962. The role of the neck in the movements of the giraffe. Journal of Mammalogy. 43: 88-97.

Folkow, B. 1991. Giraffe, rats, and man - what is the importance of the "structural factor" in normo- and hypertensive states? Clinical and Experimental Pharmacology and Physiology. 18: 3-11.

Goetz, R.H. 1955. Preliminary observations on the circulation of the giraffe. Transactions of the American College of Cardiologists. 5: 39-48.

Goetz, R.H. \& Budtz-Olsen, O. 1955. Scientific safari- the circulation of the giraffe . South African Medical Journal. 29:773-776.

Goetz, R.H. \& Keen, E.N. 1957. Some aspects of the cardiovascular system in the giraffe. Angiology 8: 542-564.

Goetz, R.H., Warren, J.V., Gauer, O.H., Patterson, J.L., Doyle, J.T., Keen, E.N. \& McGregor, M. 1960. Circulation of the giraffe. Circulation Research 8: 1049-1058.

Hall-Martin, A.J. 1977. Giraffe weight estimation using dissected leg weight and body measurements. Journal of Wildlife Management. 4: 740-745.

Hargens, A.R., Millard, R.W., Pettersson, K. \& Johansen, K. 1987. Gravitational haemodynamics and oedema prevention in the giraffe. Nature 329:59-60.

Hargens, A.R., Gershuni, D.H., Danzig, L.A., Millard, R.W. \& Pettersson, K. 1988. Tissue adaptations to gravitational stress: newborn versus adult giraffes. Physiologist 31: S110-S113.

Hicks, J.W. \& Munis, J.R. 2005. The siphon controversy counterpoint: the brain need not be "baffling". American Journal of Physiology: Regulatory, Integrative, Comparative Physiology. 289: 629-632.

Holt, J.P. 1959. Flow of liquids through collapsible tubes. Circulation Research 7: 342-353.

Holt, J. P., Rhode, E.A. \& Kines, H. 1968. Ventricular volumes and body weight in mammals. American Journal of Physiology. 215:704-715.

Jefferson, J.W. 1971. Electrocardiographic and phonocardiographic findings in a reticulated giraffe. Journal of the American Veterinary Medical Association. 159: 602-604.

Keen, E.N. \& Goetz, R.H. 1957. Cardiovascular anatomy of a foetal giraffe. Acta Anatomica. 31: 562-571.

Kimani, J.K., Mbuva, R.N. \& Kinyama, R.M. 1991. Sympathetic innervation of the hindlimb arterial system in the giraffe (Giraffa camelopardalis) Anatomical Record. 229: 103-108.

Langman, V.A. 1973. The immobilization and capture of giraffe. South African Journal of Science. 69:200-203.

Lawrence, W.E. \& Rewell, R.E. 1948. The cerebral blood supply in the Giraffidae. Proceedings of the Zoological Society (London) 118: 202- 212. 
Linton, R.A.F., Taylor P.M., Linton, N.W.F., Flach, E.J., O’Brien, T.K. \& Band D.M. 1999. Cardiac output measurement in an anaesthetized giraffe. Veterinary Record 145(17): 498-499.

McCalden, T.A., Borsook, D., Mendelow, A.D., Shimell, C.J., de Vos V., Pieterse P.C. \& de Klerk, B. 1977. Autoregulation and haemodynamics of giraffe carotid blood flow. South African Journal of Science. 73: 278-279.

Millard, A.R., Hargens, A.R., Johansen, K., Pettersson, K., Burroughs, R., Meltzer, D.G.A., Gershuni, D.H., \& van Hoven, W. 1986. Baroreflex modulates heart rate in the giraffe. Federation Proceedings 45:758.

Mitchell, G., Bobbitt, J.P. \& Devries, S. 2008. Cerebral perfusion pressure in giraffe: Modelling the effects of head raising and -lowering. Journal of Theoretical Biology. 252:98-108.

Mitchell, G. \& Hattingh, J. 1993. Giraffe colloid osmotic pressure and oedema. South African Journal of Science 89:569-570.

Mitchell, G., Maloney, S.K., Mitchell D. \& Keegan, D.J. 2006. The origin of mean arterial and jugular venous blood pressures in giraffes. Journal of Experimental Biology. 209:2515-2524.

Mitchell, G. \& Skinner, J.D. 1993. How giraffe adapt to their extraordinary shape. Transactions of the Royal Society of South Africa. 48: 207 - 218.

Mitchell, G., van Sittert, S. \& Skinner, J.D. 2009. The structure and function of giraffe jugular vein valves. South African Journal of Wildlife Research. (in press)

Munis, J.R. \& Lozada, L.J. 2000. Giraffes, siphons, and Starling resistors. Cerebral perfusion pressure revisited. Journal of Neurological Anesthesiology. 12: 290-296.

Nilsson, O., Booj, S., Dahlstrom, A., Hargens, A.R., Millard R.W. \& Pettersson K. 1988. Sympathetic innervation of the cardiovascular system in the giraffe. Blood Vessels 25: 299-307.

Paton, J.F.R., Dickinson, C. J. \& Mitchell G. 2009. Harvey Cushing and the regulation of blood pressure in giraffe, rats and man: introducing the Cushing's mechanism. Experimental Physiology. 94:11-17.

Patterson, J.L., Goetz, R.H., Doyle, J.T., Warren, J.V., Gauer, O.H., Detweiler, D.K., Said, S.I., Hoernicke, H., McGregor, M., Keen, E.N., Smith, M.H., Hardie, E.L., Reynolds, M., Flatt, W.P. \& Waldo, D.R. 1965.

cardiorespiratory dynamics in the ox and giraffe, with comparative observations on man and other mammals. Annals of the New York Academy of Sciences 127:393-413.

Patterson, J.L., Warren, J.V., Doyle, J.T., Gauer, O., Keen, E.N. \& Goetz, R.H. 1957. Circulation and respiration in the giraffe. Journal of Clinical Investigation. 36:919.

Pedley, T.J., Brook B.S. \& Seymour R.S. 1996. Blood pressure and flow rate in the giraffe jugular vein. Philosophical Transactions of the Royal Society (London), B. 351:855-866.

Prothero, J. 1979. Heart weight as a function of body weight in mammals. Growth. 43:139-150.

Rossof, A.H. 1972. An electrocardiographic study of the giraffe. American Heart Journal 83:142-143.

Seymour, R.S. \& Blaylock, A.J. 2000. The principle of LaPlace and scaling of ventricular wall stress and blood pressure in mammals and birds. Physiological and Biochemical Zoology. 73:389-405.

Seymour, R.S. \& Johansen, K. 1987. Blood flow up hill and downhill: Does a siphon facilitate circulation above the heart. Comparative Biochemistry and Physiology A. 88: 167-170.

Seymour, R.S., Hargens, A.R. \& Pedley, T.J. 1993. The heart works against gravity. American Journal of Physiology 265: R715-R720.

Seymour, R.S. 2000. Model analogues in the study of cephalic circulation. Comparative Biochemistry and Physiology 


\section{A. 125: 517-524.}

Schmidt-Nielsen, K. 1984. Scaling: Why is animal size so important? Cambridge University Press.

Skinner, J.D. \& Hall-Martin, A.J. 1975. A note on foetal growth and development of the giraffe, Giraffa camelopardalis giraffa. Journal of Zoology, London. 177:73-79.

Stahl, W.R. 1967. Scaling of respiratory variables in mammals. Journal of Applied Physiology 22: 453-460.

van Citters, R.L., Kemper, W.S. \& Franklin D.L. 1966. Blood pressure responses of wild giraffes studied by radio telemetry. Science 152: 384-386.

van Citters, R.L., Kemper, W.S. \& Franklin D.L. 1968. Blood flow and pressure in the giraffe carotid artery. Comparative Biochemistry and Physiology 24: 1035-1042.

van Citters, R.L., Franklin, D.L., Vatner, S.F., Patrick, T. \& Warren, J.V. 1969. Cerebral haemodynamics in the giraffe. Transactions of the Association of American Physicians 82:293- 304.

Zippel, K.C., Lillywhite, H.B., \& Mladinich, R.J. 2001. New vascular system in reptiles: anatomy and postural haemodynamics of the vertebral venous plexus in snakes. Journal of Morphology. 250:173-184. 
Table 1: Study Animals

\begin{tabular}{|c|c|c|c|}
\hline Animals & $\mathrm{N}$ & $\begin{array}{c}\text { Body mass range } \\
(\mathrm{kg})\end{array}$ & Age range \\
\hline Foetuses & 10 & $18-77$ & $274-408$ days \\
\hline Males & 22 & $187-1441$ & $0.6->20$ years \\
\hline Females & 24 & $147-1029$ & $0.4->20$ years \\
\hline
\end{tabular}

Table 2: Allometric equations for heart dimensions using body mass ( $\mathrm{Mb}, \mathrm{kg})$ and neck length $(\mathrm{NL}, \mathrm{cm})$ as covariates

\begin{tabular}{|c|c|c|c|c|}
\hline Variable & Foetus & Postnatal & Predicted & Reference $^{\#}$ \\
\hline Heart mass(kg) & $.006 * \mathrm{Mb}^{1.03}$ & $.010 * \mathrm{Mb}^{0.90}$ & $0.004 * \mathrm{Mb}^{1.05}$ & $\begin{array}{l}\text { Holt,1968; Prothero,1979; } \\
\text { Seymour \& Blaylock,2000 }\end{array}$ \\
\hline Mh:Mb (\%) & $0.64 * \mathrm{Mb}^{0.03}$ & $1.0 * \mathrm{Mb}^{-0.10}$ & $0.400 * \mathrm{Mb}^{0.05}$ & $\begin{array}{l}\text { Holt,1968;Prothero,1979; } \\
\text { Seymour \& Blaylock,2000 }\end{array}$ \\
\hline $\begin{array}{c}\text { Heart } \\
\text { Length }(\mathrm{cm})\end{array}$ & $2.6 * \mathrm{Mb}^{0.36}$ & $3.4 * \mathrm{Mb}^{0.29}$ & - & - \\
\hline $\begin{array}{l}\text { Heart Diameter } \\
\qquad(\mathrm{cm})\end{array}$ & $1.8^{*} \mathrm{Mb}^{0.39}$ & $2.7 * \mathrm{Mb}^{0.29}$ & - & - \\
\hline $\begin{array}{l}\text { Left ventricle } \\
\text { wall } \\
\text { thickness }(\mathrm{cm}) \\
\end{array}$ & $0.53 * \mathrm{Mb}^{0.36}$ & $0.48 * \mathrm{Mb}^{0.38}$ & $0.26 * \mathrm{Mb}^{0.42}$ & $\begin{array}{l}\text { Calder,1996; Seymour \& } \\
\text { Blaylock,2000 }\end{array}$ \\
\hline $\begin{array}{l}\text { Left ventricle } \\
\text { wall } \\
\text { thickness }(\mathrm{cm})\end{array}$ & $0.07 * \mathrm{NL}^{0.86}$ & $0.08 * \mathrm{NL}^{0.84}$ & - & - \\
\hline $\begin{array}{l}\text { Right ventricle } \\
\text { wall } \\
\text { thickness }(\mathrm{cm})\end{array}$ & $1.0^{*} \mathrm{Mb}^{0.18}$ & $0.34 * \mathrm{Mb}^{0.28}$ & - & - \\
\hline $\begin{array}{l}\text { Interventricular } \\
\text { wall } \\
\text { thickness }(\mathrm{cm})\end{array}$ & $0.53 * \mathrm{Mb}^{0.30}$ & $0.42 * \mathrm{Mb}^{0.35}$ & - & - \\
\hline $\begin{array}{l}\text { Interventricular } \\
\text { wall } \\
\text { thickness }(\mathrm{cm})\end{array}$ & $0.08 * \mathrm{NL}^{0.77}$ & $0.08 * \mathrm{NL}^{0.79}$ & - & - \\
\hline
\end{tabular}

\#: for predicted equations 
Table 3: Allometric equations for dynamic cardiovascular variables using body mass $(\mathrm{Mb}$, $\mathrm{kg}$ ) as the covariate

\begin{tabular}{|c|c|c|c|c|}
\hline Variable & Foetus & Postnatal & Predicted & Reference $^{\#}$ \\
\hline $\begin{array}{l}\text { Cardiac Output } \\
(\mathrm{L} / \mathrm{min})\end{array}$ & - & $0.211 * \mathrm{Mb}^{0.78}$ & $0.211 * \mathrm{Mb}^{0.78}$ & $\begin{array}{c}\text { Stahl,1967; Holt,1968; } \\
\text { Seymour \& } \\
\text { Blaylock,2000 }\end{array}$ \\
\hline $\begin{array}{l}\text { Stroke volume } \\
\text { (ml) }\end{array}$ & $1.12 * \mathrm{Mb}^{1.07}$ & $.55^{*} \mathrm{Mb}^{1.04}$ & $1.05^{*} \mathrm{Mb}^{1.0}$ & $\begin{array}{c}\text { Stahl,1967; Holt,1968; } \\
\text { Seymour \& } \\
\text { Blaylock,2000 }\end{array}$ \\
\hline $\begin{array}{l}\text { Heart Rate } \\
\quad(\mathrm{bpm})\end{array}$ & $188.4^{*} \mathrm{Mb}^{-.29}$ & $418.2 * \mathrm{Mb}^{-.28}$ & $218.8^{*} \mathrm{Mb}^{-0.24}$ & $\begin{array}{l}\text { Stahl,1967; Holt,1968; } \\
\text { Calder,1981; Seymour \& } \\
\text { Blaylock,2000 }\end{array}$ \\
\hline $\begin{array}{l}\text { Mean Systemic } \\
\text { Pressure }(\mathrm{mmHg})\end{array}$ & $89.5^{*} \mathrm{Mb}^{0.036}$ & $51.5^{*} \mathrm{Mb}^{0.21}$ & $89.3^{*} \mathrm{Mb}^{0.04}$ & $\begin{array}{l}\text { Calder,1996; Seymour \& } \\
\text { Blaylock,2000 }\end{array}$ \\
\hline $\begin{array}{l}\text { Total Peripheral } \\
\text { resistance(units) }\end{array}$ & $424.0 * \mathrm{Mb}^{-.74}$ & $244.1 * \mathrm{Mb}^{-.57}$ & $454.8^{*} \mathrm{Mb}^{-0.76}$ & $\begin{array}{l}\text { Holt,1968; Calder,1996; } \\
\text { Seymour \& } \\
\text { Blaylock,2000 }\end{array}$ \\
\hline $\begin{array}{c}\text { Systolic } \\
\text { pressure }(\mathrm{mmHg})\end{array}$ & $127.9 * \mathrm{Mb}^{0.02}$ & $78.0 * \mathrm{Mb}^{0.18}$ & $115.2 * \mathrm{Mb}^{0.05}$ & $\begin{array}{c}\text { Seymour \& } \\
\text { Blaylock,2000 }\end{array}$ \\
\hline $\begin{array}{c}\text { Diastolic } \\
\text { pressure }(\mathrm{mmHg})\end{array}$ & $68.1^{*} \mathrm{Mb}^{0.03}$ & $39.6 * \mathrm{Mb}^{0.24}$ & $78.7 * \mathrm{Mb}^{0.05}$ & $\begin{array}{c}\text { Seymour \& } \\
\text { Blaylock,2000 }\end{array}$ \\
\hline $\begin{array}{c}\text { Mean } \\
\text { Pulmonary } \\
\text { Pressure(mmHg) }\end{array}$ & $104.1 * \mathrm{Mb}^{-.15}$ & $104.1 * \mathrm{Mb}^{-.15}$ & - & - \\
\hline
\end{tabular}

\#: for predicted equations 
Table 4: The range of values predicted for the 10 fetal and 46 postnatal giraffes in this study and for a $775 \mathrm{~kg}$ giraffe

\begin{tabular}{|c|c|c|c|}
\hline Variable & $775 \mathrm{~kg}$ giraffe & $\begin{array}{l}\text { Postnatal } \\
\text { range }\end{array}$ & $\begin{array}{l}\text { Foetal } \\
\text { range }\end{array}$ \\
\hline Body Mass(kg) & 775 & $147-1441$ & $18-77$ \\
\hline Heart Mass(kg) & 4.0 & $1.1-7.8$ & $0.134-0.534$ \\
\hline Mh:Mb(\%) & 0.52 & $0.74-0.40$ & $0.93-0.63$ \\
\hline $\begin{array}{c}\text { Heart } \\
\text { Length }(\mathrm{cm})\end{array}$ & 23.4 & $14-32$ & $7-13$ \\
\hline Heart Diameter & 18.6 & $12-21$ & $5-10$ \\
\hline $\begin{array}{l}\text { Left ventricle } \\
\text { wall thickness } \\
\quad(\mathrm{cm})\end{array}$ & 6.0 & $3.1-8.0$ & $1.5-2.5$ \\
\hline $\begin{array}{l}\text { Right ventricle } \\
\text { wall } \\
\text { thickness }(\mathrm{cm})\end{array}$ & 2.2 & $1.2-2.5$ & $1.2-1.8$ \\
\hline $\begin{array}{l}\text { Interventricular } \\
\text { wall } \\
\text { thickness }(\mathrm{cm})\end{array}$ & 4.3 & $3.0-5.7$ & $1.3-2.0$ \\
\hline $\begin{array}{l}\text { Cardiac Output } \\
(\mathrm{L} / \mathrm{min})\end{array}$ & 37.8 & $10-61$ & $2.0-6.3$ \\
\hline $\begin{array}{c}\text { Stroke } \\
\text { volume }(\mathrm{ml})\end{array}$ & 556.2 & $87-1117$ & $11-52$ \\
\hline Heart Rate(bpm) & 64.9 & $53-127$ & $126-202$ \\
\hline $\begin{array}{c}\text { Mean Syst. } \\
\text { Arterial } \\
\text { Pressure }(\mathrm{mmHg})\end{array}$ & 208.2 & $147-237$ & $100-105$ \\
\hline $\begin{array}{c}\text { Mean Pulm. } \\
\text { Arterial } \\
\text { Pressure }(\mathrm{mmHg})\end{array}$ & 38.4 & $35-49$ & $54-68$ \\
\hline $\begin{array}{l}\text { Total Peripheral } \\
\text { Resistance(units) }\end{array}$ & 5.5 & $4-14$ & $17-50$ \\
\hline
\end{tabular}




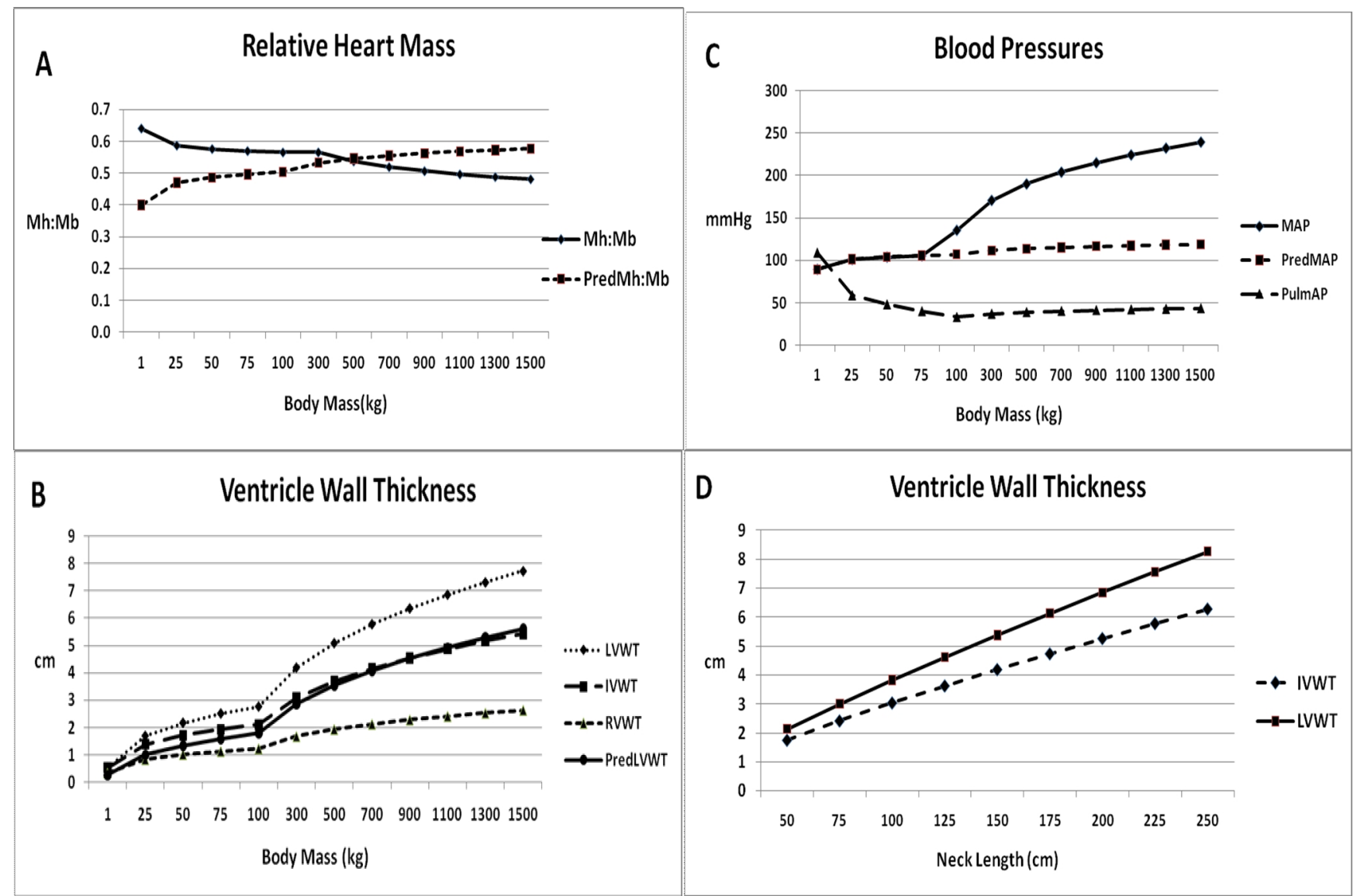

Fig.1. Changes in relative heart mass (A), ventricular wall thicknesses (B), and mean blood pressures (C) with increases in body mass, and changes in ventricle wall thickness as neck length increases (D). Note that the relative heart mass (A) of giraffes declines with growth whereas predicted relative mass increases (see text). In B and D ventricle wall hypertrophy increases as body mass and neck length increase. In $\mathrm{C}$ systemic blood pressure in giraffes increases after birth $(=\mathrm{Mb}$ of $100 \mathrm{~kg})$ and is significantly higher than predicted pressures for same body mass mammals. Mean pulmonary artery pressure decreases in fetal life but after birth increases slightly with growth. 


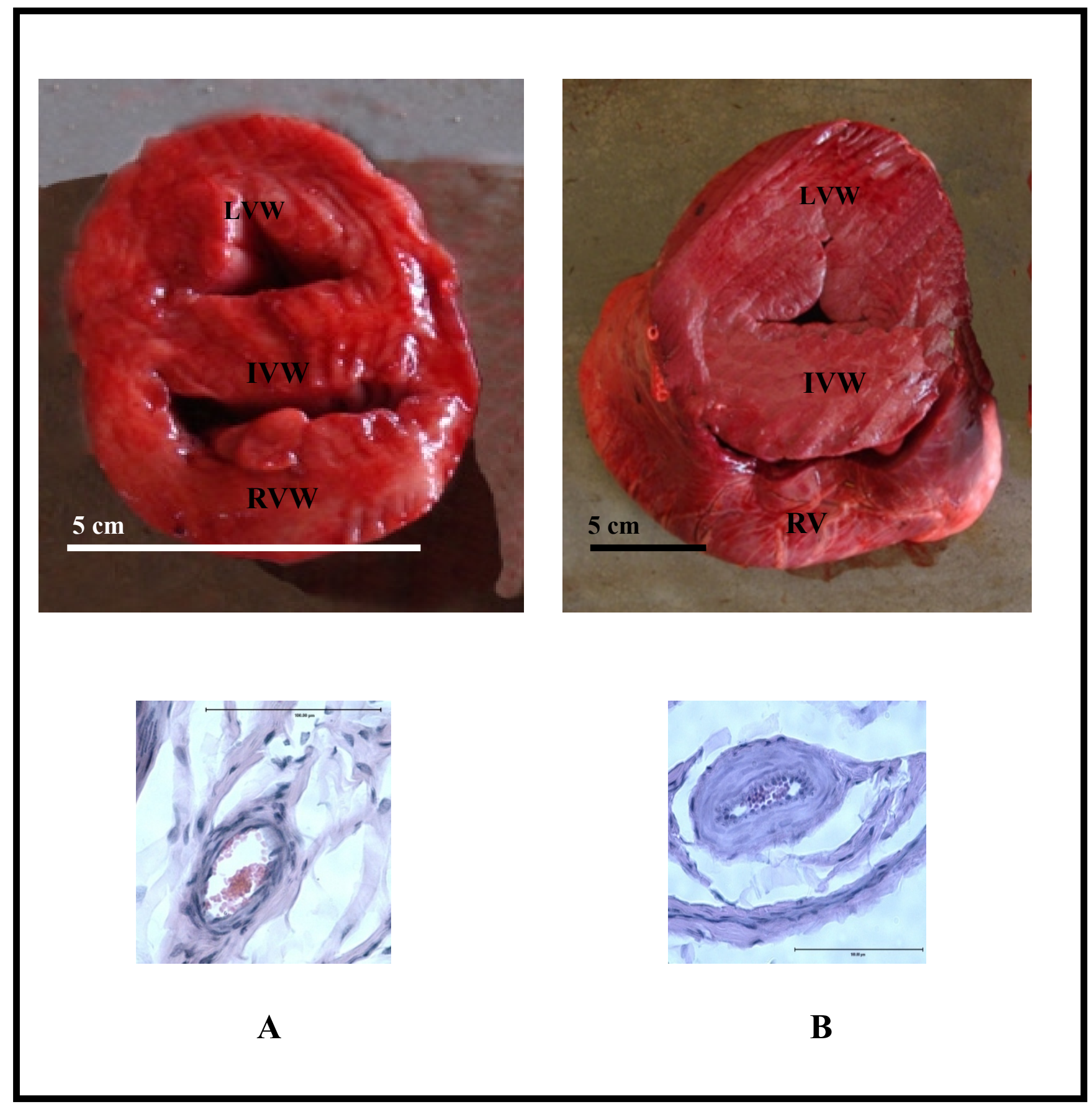

Fig. 2. A. Cross-section of the mid-point of the ventricles and of a mesenteric arteriole in a $30 \mathrm{~kg}$ ( 315 day) foetus, and B, in a $1300 \mathrm{~kg}$ mature male giraffe. Note that both the ventricles and the arterioles are hypertrophied in the adult compared with the foetus. 